\title{
Reproductive Success in Fish Stocks Can Be Reproduced by Environmental Factors Alone
}

\author{
Kazumi Sakuramoto \\ Department of Ocean Science and Technology, Tokyo University of Marine Science and Technology, Minato, Japan \\ Email: sakurak@kaiyodai.ac.jp
}

How to cite this paper: Sakuramoto, K. (2021) Reproductive Success in Fish Stocks Can Be Reproduced by Environmental Factors Alone. Open Access Library Journal, 8: e7636.

https://doi.org/10.4236/oalib.1107636

Received: June 11, 2021

Accepted: July 20, 2021

Published: July 23, 2021

Copyright $\odot 2021$ by author(s) and Open Access Library Inc.

This work is licensed under the Creative Commons Attribution International License (CC BY 4.0).

http://creativecommons.org/licenses/by/4.0/

\section{(c) (i) Open Access}

\begin{abstract}
This study showed that reproductive successes (RPS) in fish stocks could be reproduced using only environmental factors. As the environmental factors, the monthly Arctic oscillation index and Pacific decadal oscillation were used. The RPS of 12 stocks harvested around Japan were reproduced. The results were as follows: the fitness between observed and reproduced RPS, and the number of the independent variables necessary for reproducing the RPS differed by stock. However, the fluctuations of RPS could be reproduced using only the environmental factors. These results support the validity of the mechanism proposed by Sakuramoto regarding the factors that drive the fluctuation in RPS. That is, the fluctuation in RPS occurs due to conditions determined by environmental factors, and is not a density-dependent effect.
\end{abstract}

\section{Subject Areas \\ Marine Biology}

\section{Keywords}

Reproductive Successes, RPS, Chub Mackerel, Blue Mackerel, Alaska Pollock, Japanese Sardine, Japanese Anchovy, Japanese Common Squid, Arabesque Greenling, Splendid Alfonsino

\section{Introduction}

Reproductive successes (RPS) largely fluctuate every year. Such fluctuations cause the large variability in stock abundance. Therefore, the mechanism that controls the fluctuations in RPS is very important for managing fishery resources. Generally, it has been considered that a density-dependent effect is the essential factor driving fluctuations in RPS, while environmental factors have 
been considered only a perturbation factor.

However, Sakuramoto [1] [2] showed that the RPS of Pacific stock of Japanese sardines and Pacific bluefin tuna could be reproduced using only environmental factors. The model did not assume a density-dependent effect. As the main environmental factors, the sea surface temperature in the Kuroshio extension area was used for the former stock, and the monthly index of Arctic Oscillation (AO) and Pacific Decadal Oscillation (PDO) were used for the latter stock.

The aim of this paper is to investigate whether or not the mechanism proposed by Sakuramoto [1] [2] could be adapted to other stocks. That is, whether RPS could be reproduced using only environmental factors. In this study, only $\mathrm{AO}$ and PDO by monthly index were used as the environmental factors, and we attempted to reproduce the RPS for 12 stocks harvested around Japan.

The stocks investigated were: 1) Pacific stock of Chub mackerel (Scomber japonicus); 2) Tushima warm current stock of Chub mackerel; 3) Pacific stock of Blue mackerel (Scomber australasicous); 4) East China Sea stock of Blue mackerel; 5) Pacific stock of Alaska pollock (Teragra chalcogramma); 6) Northern Sea of Japan stock of Alaska pollock; 7) Pacific stock of Japanese sardine (Sardinops melanostictus); 8) Pacific stock of Japanese anchovy (Engraulis japonicus); 9) Autumn-spawning group of Japanese common squid (Todarodes pacificus); 10) Winter-spawning group of Japanese common squid; 11) Northern Sea of Japan stock of Arabesque greenling (Pleurogrammus azonus); 12) Pacific stock of Splendid alfonsino (Beryx splendens).

\section{Materials and Methods}

\subsection{Data}

The data for the stocks used in this study were provided by the Fisheries Agency and Fisheries Research Agency Japan [3]. The environmental factors used in this study were the monthly index of the AO [4] and PDO [5].

\subsection{Calculation of correlation coefficients between RPS and A0, and RPS and PDO, by month}

The correlation coefficient between RPS in year $t\left(\mathrm{RPS}_{t}\right)$ and the AO in month $m$ of year $t-i,\left(\mathrm{AO}_{m, t-i}\right)$ were calculated. Here $m, t$ and $i$ denote the month, year and time lag, respectively. The correlation coefficient between RPS in year $t$ $\left(\mathrm{RPS}_{t}\right)$ and the PDO in month $m$ of year $t-i,\left(\mathrm{PDO}_{m, t-i}\right)$ were also calculated. Subsequently, $\mathrm{AO}_{m, t-i}$ and $\mathrm{PDO}_{m, t-i}$ that showed statistical significance were used as candidate independent variables in order to reproduce the natural logarithm of RPS $[\ln (\mathrm{RPS})]$. That is,

$$
\ln \left(\mathrm{RPS}_{t}\right)=a_{0}+\sum_{m=1}^{12} \sum_{i=0}^{p} a_{u} \mathrm{AO}_{m, t-i}+\sum_{m=1}^{12} \sum_{i=0}^{q} a_{v} \mathrm{PDO}_{m, t-i}
$$

Here, $a_{u}$ and $a_{v}$ were the partial regression coefficients that were used to reproduce the $\ln$ (RPS). They were determined by each stock based on the sum of square values of observed and reproduced $\ln$ (RPS). 


\section{Results}

\section{Independent Variables and the Partial Regression Coefficients Used to Reproduce the In(RPS)}

Table 1 lists the independent variables and partial regression coefficients estimated based on the sum of square values between observed and reproduced $\ln (\mathrm{RPS})$. For instance, in the case of the Pacific stock of Chub mackerel, February and April of AO in year $t-2$, April, May and August of PDO in year $t-1$, and February, March, August, September and November of PDO in year- 2 were used as the independent variables to reproduce the $\ln$ (RPS). In general, for epipelagic fishes such as mackerel, sardine and anchovy, etc. (except the Blue mackerel of the East China Sea stock), it was necessary to use many independent variables to reproduce $\ln$ (RPS) compared to demersal fishes (except the Splended alfonsino of the Pacific stock). Two stocks of Common squid are also epipelagic fishes; however, they required fewer independent variables. This may have been partly due to their short life span.

Figure 1 shows the observed (black) and reproduced (red) $\ln$ (RPS) for the Pacific stock of Chub mackerel (a) and the Tushima warm current stock (b). In general, when observed $\ln$ (RPS) was extremely high or low, it was difficult to reproduce those levels exactly; however, the whole tendency of the observed $\ln$ (RPS) was relatively well reproduced using the model proposed here.

Figure 2 shows the observed and reproduced $\ln$ (RPS) for the Pacific stock of Blue mackerel (a) and the East China Sea stock (b). In Figure 2, the observed and reproduced $\ln$ (RPS) did not coincide well in several years, however, the whole tendency of the observed $\ln$ (RPS) was relatively well reproduced. Figure 3 presents the observed and reproduced $\ln$ (RPS) for the Pacific stock of Alaska pollock (a) and Northern Sea of Japan stock (b). In Figure 3(a), the observed $\ln$ (RPS) after 2010 were substantially lower than the reproduced $\ln$ (RPS). While the reason why is not clear at this stage, it is possible that observed $\ln$ (RPS) was underestimated due to overestimation of spawning stock biomass and/or underestimation of recruitment. In the case of the Northern Sea of Japan stock (b), the observed and reproduced $\ln$ (RPS) did not coincide well. For this stock, other environmental factors should be incorporated to explain the fluctuation in $\ln$ (RPS). Further analysis will be needed.

Figure 4 contains the observed and reproduced $\ln$ (RPS) for the Pacific stock of Japanese sardine (a) and the Pacific stock of Japanese anchovy (b). The fluctuations of these two species were extremely large; however, the reproduced $\ln$ (RPS) was in good agreement with the observed $\ln$ (RPS).

Figure 5 shows the observed and reproduced $\ln$ (RPS) for the Autumn-spawning group of Japanese common squid (a) and that of the Winter-spawning group (b). The fitness was better for the former stock than for the latter. Figure 6 presents the observed and reproduced $\ln$ (RPS) for the Northern Sea of Japan stock of Arabesque greenling (a) and the Pacific stock of Splendid alfonsino (b). For the former stock, only five independent variables were needed, even though, except for the first couple of years, the fitness of observed and reproduced $\ln$ (RPS) were very high. 
Table 1. Independent variables, the number of the independent variables (n) and the partial regression coefficients estimated to reproduce $\ln (\mathrm{RPS})$.

\begin{tabular}{|c|c|c|c|}
\hline \multicolumn{2}{|c|}{$\begin{array}{l}\text { Chub mackerel (Pacific) } \\
\qquad(1970-2017)\end{array}$} & \multicolumn{2}{|c|}{$\begin{array}{l}\text { Chub mackerel (Tushima warm current ) } \\
(1973-2018)\end{array}$} \\
\hline Const. & 1.98390 & Const. & 1.89070 \\
\hline $\mathrm{AO}_{t-2,2}$ & 0.23268 & $\mathrm{AO}_{t-1,5}$ & 0.12341 \\
\hline $\mathrm{AO}_{t-2,4}$ & 0.34062 & $\mathrm{AO}_{t-2,2}$ & 0.13642 \\
\hline $\mathrm{PDO}_{t-1,4}$ & -0.27213 & $\mathrm{AO}_{t-5,4}$ & 0.19680 \\
\hline $\mathrm{PDO}_{t-1,5}$ & 0.29238 & $\mathrm{AO}_{t-6,2}$ & 0.14273 \\
\hline $\mathrm{PDO}_{t-1,8}$ & -0.34593 & $\mathrm{PDO}_{t-2,3}$ & 0.17045 \\
\hline $\mathrm{PDO}_{t-2,2}$ & -0.40763 & $\mathrm{PDO}_{t-2,4}$ & -0.21082 \\
\hline $\mathrm{PDO}_{t-2,3}$ & 0.47524 & $\mathrm{PDO}_{t-3,7}$ & -0.12460 \\
\hline $\mathrm{PDO}_{t-2,8}$ & -0.32773 & $\mathrm{PDO}_{t-3,10}$ & 0.13378 \\
\hline $\mathrm{PDO}_{t-2,11}$ & 0.09496 & $\mathrm{PDO}_{t-3,11}$ & -0.15647 \\
\hline$n$ & 9 & $n$ & 9 \\
\hline \multicolumn{2}{|c|}{$\begin{array}{c}\text { Blue mackerel (Pacific) } \\
(1995-2018)\end{array}$} & \multicolumn{2}{|c|}{$\begin{array}{l}\text { Blue mackerel (East China Sea ) } \\
\qquad(1992-2017)\end{array}$} \\
\hline Const. & 1.89739 & Const. & 1.67763 \\
\hline $\mathrm{AO}_{t, 4}$ & -0.24328 & $\mathrm{AO}_{t, 2}$ & -0.08746 \\
\hline $\mathrm{AO}_{t-2,8}$ & 0.75738 & $\mathrm{AO}_{t, 5}$ & -0.14036 \\
\hline $\mathrm{AO}_{t-3,9}$ & -0.46902 & $\mathrm{AO}_{t-1,3}$ & 0.06622 \\
\hline $\mathrm{AO}_{t-4,3}$ & -0.11878 & $\mathrm{AO}_{t-2,3}$ & -0.12918 \\
\hline $\mathrm{AO}_{t-4,8}$ & 0.32984 & & \\
\hline $\mathrm{AO}_{t-6,9}$ & -0.20506 & & \\
\hline $\mathrm{PDO}_{t-4,5}$ & 0.08832 & & \\
\hline$n$ & 7 & $n$ & 4 \\
\hline \multicolumn{2}{|c|}{$\begin{array}{l}\text { Alaska pollock (Pacific) } \\
\qquad(1981-2017)\end{array}$} & \multicolumn{2}{|c|}{$\begin{array}{l}\text { Alaska pollock (Japan Sea ) } \\
(1980-2017)\end{array}$} \\
\hline Const. & 1.7079 & Const. & 0.4624 \\
\hline $\mathrm{PDO}_{t, 7}$ & 0.3925 & $\mathrm{PDO}_{t, 5}$ & -0.116 \\
\hline $\mathrm{PDO}_{t, 8}$ & -0.2772 & $\mathrm{PDO}_{t, 7}$ & 0.3429 \\
\hline $\mathrm{PDO}_{t, 9}$ & 0.1915 & $\mathrm{PDO}_{t, 8}$ & -0.1433 \\
\hline $\mathrm{PDO}_{t-1,8}$ & 0.6473 & $\mathrm{PDO}_{t-1,7}$ & 0.4079 \\
\hline $\mathrm{PDO}_{t-1,9}$ & -0.6302 & $\mathrm{PDO}_{t-1,8}$ & -0.2679 \\
\hline$n$ & 5 & $n$ & 5 \\
\hline
\end{tabular}




\section{Continued}

\begin{tabular}{|c|c|c|c|}
\hline \multicolumn{2}{|c|}{$\begin{array}{l}\text { Japanese sardine (Pacific) } \\
\quad(1976-2018)\end{array}$} & \multicolumn{2}{|c|}{$\begin{array}{l}\text { Japanese anchovy (Pacific) } \\
\qquad(1978-2018)\end{array}$} \\
\hline Const. & 3.0949 & Const. & 5.26657 \\
\hline $\mathrm{AO}_{t, 2}$ & -0.1215 & $\mathrm{PDO}_{t-1,2}$ & 0.39241 \\
\hline $\mathrm{AO}_{t-6,8}$ & -0.5742 & $\mathrm{PDO}_{t-1,3}$ & -0.33866 \\
\hline $\mathrm{PDO}_{t-2,7}$ & -0.3705 & $\mathrm{PDO}_{t-1,4}$ & 0.12891 \\
\hline $\mathrm{PDO}_{t-4,3}$ & -0.4720 & $\mathrm{PDO}_{t-1,12}$ & 0.29999 \\
\hline $\mathrm{PDO}_{t-4,4}$ & 0.4451 & $\mathrm{PDO}_{t-2,3}$ & -0.21291 \\
\hline $\mathrm{PDO}_{t-5,3}$ & -0.8580 & $\mathrm{PDO}_{t-2,4}$ & 0.72990 \\
\hline $\mathrm{PDO}_{t-5,4}$ & 0.6394 & $\mathrm{PDO}_{t-2,5}$ & -0.36896 \\
\hline $\mathrm{PDO}_{t-6,2}$ & -0.6071 & $\mathrm{PDO}_{t-2,11}$ & 0.13886 \\
\hline $\mathrm{PDO}_{t-6,3}$ & 0.3197 & $\mathrm{PDO}_{t-2,12}$ & -0.10510 \\
\hline$n$ & 9 & $n$ & 9 \\
\hline \multicolumn{2}{|c|}{$\begin{array}{l}\text { Japanese common squid (Autumn) } \\
\qquad(1982-2018)\end{array}$} & \multicolumn{2}{|c|}{$\begin{array}{l}\text { Japanese common squid (Winter) } \\
(1980-2018)\end{array}$} \\
\hline Const. & 0.91943 & Const. & 1.02485 \\
\hline $\mathrm{PDO}_{t-1,10}$ & -0.08636 & $\mathrm{AO}_{t-2,4}$ & 0.17316 \\
\hline $\mathrm{PDO}_{t-2,3}$ & -0.20472 & $\mathrm{PDO}_{t-2,2}$ & 0.14731 \\
\hline $\mathrm{PDO}_{t-2,7}$ & 0.24939 & $\mathrm{PDO}_{t-2,11}$ & -0.12256 \\
\hline$n$ & 3 & $n$ & 3 \\
\hline \multicolumn{2}{|c|}{$\begin{array}{l}\text { Arabesque greenling (Pacific) } \\
\qquad(1985-2017)\end{array}$} & \multicolumn{2}{|c|}{$\begin{array}{l}\text { Splendid alfonsino (Pacific) } \\
\qquad(1999-2019)\end{array}$} \\
\hline Const. & 2.7542 & Const. & -0.71612 \\
\hline $\mathrm{AO}_{t, 10}$ & 0.1125 & $\mathrm{AO}_{t-4,7}$ & 0.73398 \\
\hline $\mathrm{AO}_{t-1,7}$ & 0.8004 & $\mathrm{AO}_{t-6,3}$ & 0.13559 \\
\hline $\mathrm{AO}_{t-1,11}$ & -0.2290 & $\mathrm{PDO}_{t-3,2}$ & -0.10703 \\
\hline $\mathrm{PDO}_{t, 4}$ & 0.1989 & $\mathrm{PDO}_{t-3,6}$ & -0.29403 \\
\hline \multirow[t]{4}{*}{$\mathrm{PDO}_{t, 5}$} & -0.4654 & $\mathrm{PDO}_{t-4,1}$ & -0.41294 \\
\hline & & $\mathrm{PDO}_{t-4,2}$ & 0.09972 \\
\hline & & $\mathrm{PDO}_{t-4,9}$ & 0.22974 \\
\hline & & $\mathrm{PDO}_{t-5,12}$ & 0.13326 \\
\hline$n$ & 5 & $n$ & 8 \\
\hline
\end{tabular}




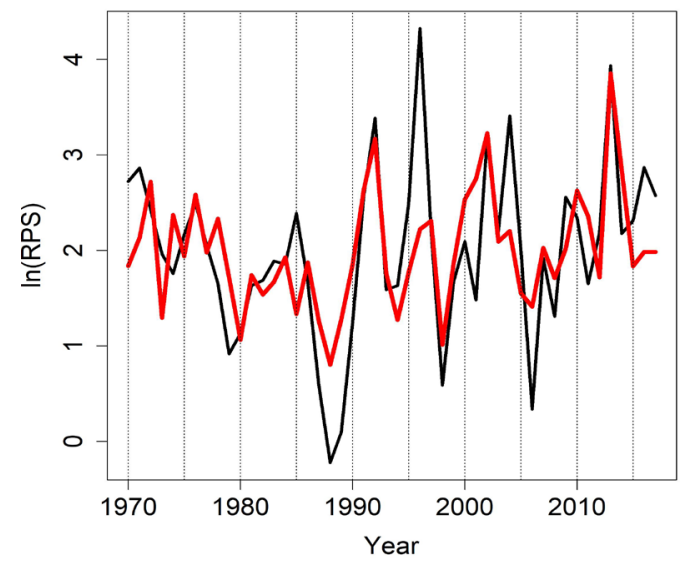

(a)

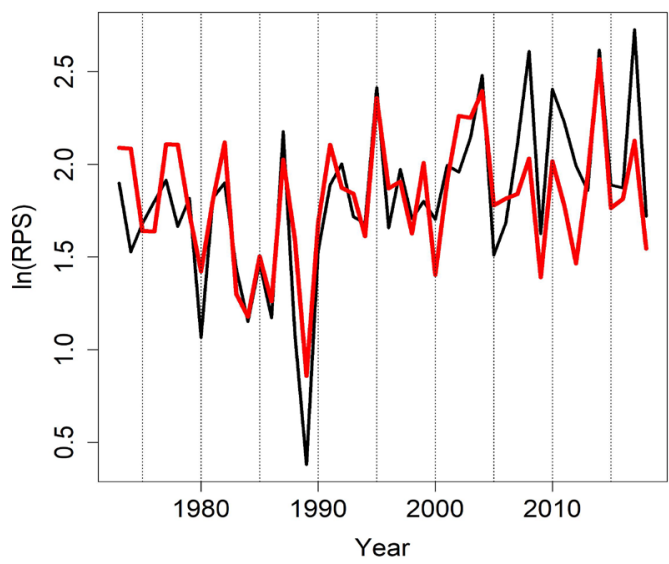

(b)

Figure 1. $\ln$ (RPS) observed (black) and reproduced (red). (a) Pacific stock of Chub mackerel; (b) Tushima warm current stock.

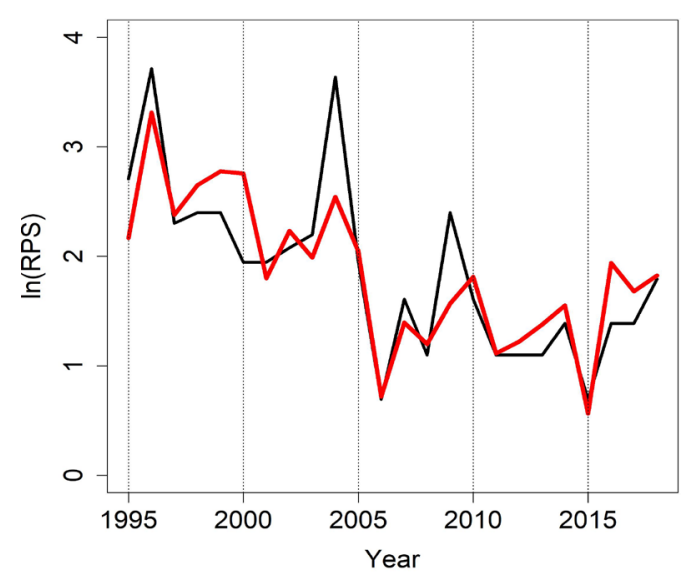

(a)

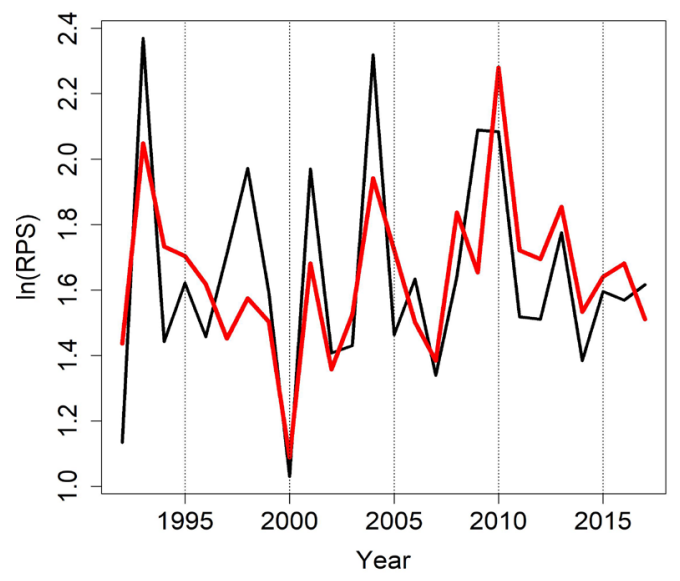

(b)

Figure 2. $\ln$ (RPS) observed (black) and reproduced (red). (a) Pacific stock of Blue mackerel; (b) East China Sea stock of Blue mackerel.

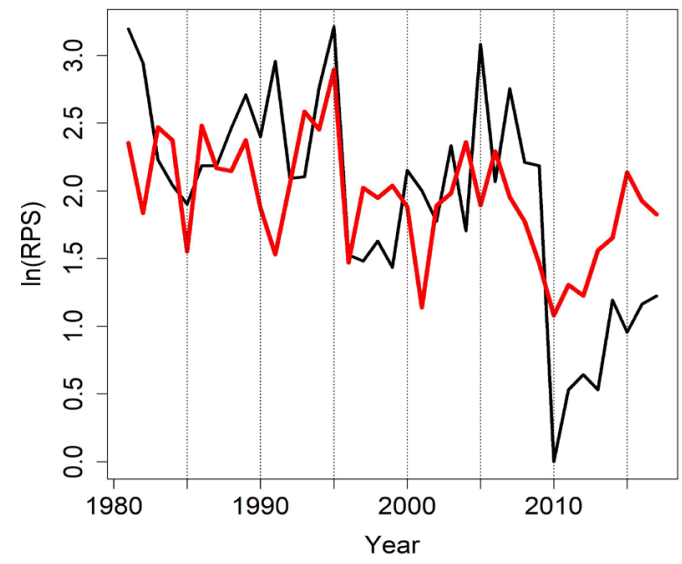

(a)

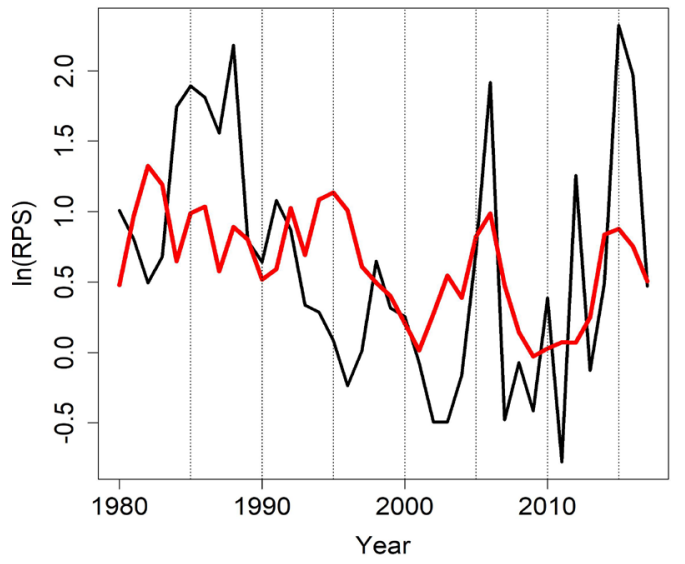

(b)

Figure 3. $\ln$ (RPS) observed (black) and reproduced (red). (a) Pacific stock of Alaska pollock; (b) Northern Sea of Japan stock of Alaska pollock. 


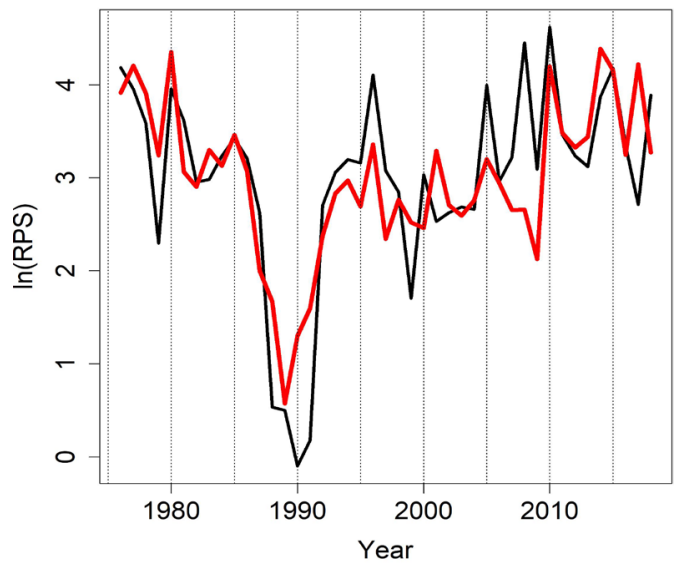

(a)

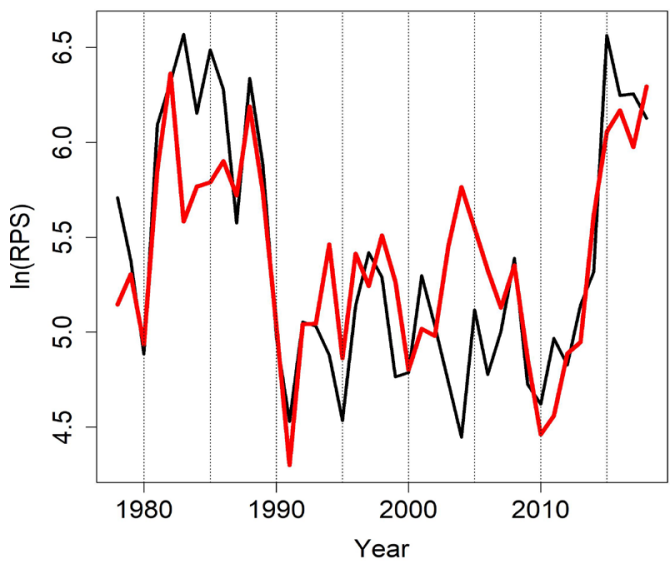

(b)

Figure 4. $\ln$ (RPS) observed (black) and reproduced (red). (a) Pacific stock of Japanese sardine; (b) Pacific stock of Japanese anchovy.

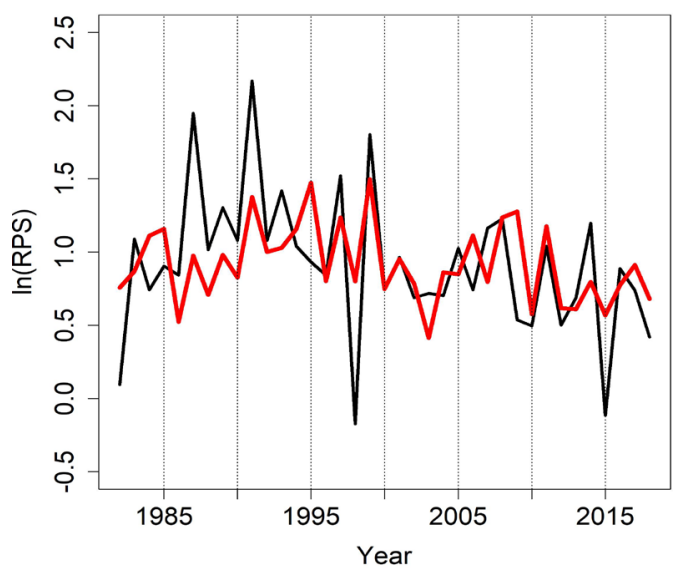

(a)

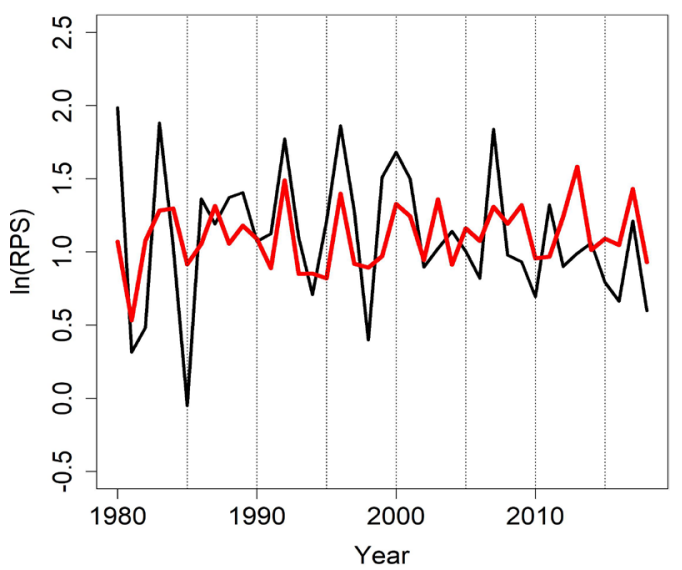

(b)

Figure 5. $\ln$ (RPS) observed (black) and reproduced (red). (a) Autumn-spawning group of Japanese common squid; (b) Winter-spawning group of Japanese common squid.

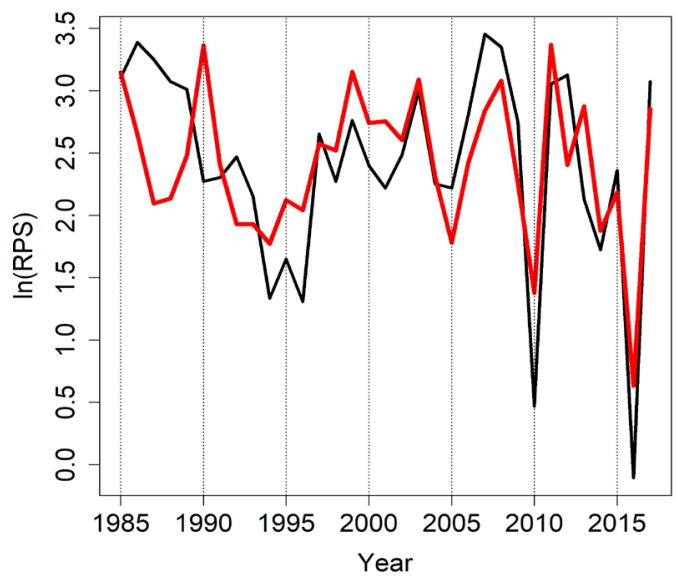

(a)

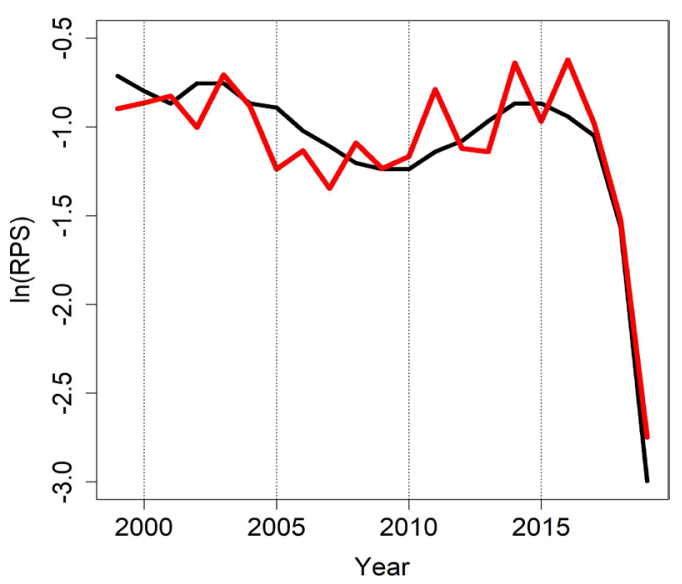

(b)

Figure 6. $\ln$ (RPS) observed (black) and reproduced (red). (a) Northern Sea of Japan stock of Arabesque greenling; (b) Pacific stock of Splendid alfonsino. 


\section{Discussion}

This study showed that RPS could be reproduced using only AO and PDO by month. A density-dependent effect, which is usually considered to be an important factor driving the RPS, was not needed to explain the large fluctuation in RPS. The models shown in this paper do not necessarily represent the best model to reproduce the RPSs, and much more reasonable models could be constructed if sufficient environmental information were available. This indicates that the important point that we should learn from this analysis is whether or not we can discover the best model to reproduce the RPS under limited environmental information. The more important point to learn from this analysis is that the overall fluctuations in RPS could be reproduced acceptably well even using the limited environmental information. This indicated that the RPS was mainly determined by environmental factors not a density-dependent effect. These results support the validity of the mechanism proposed by Sakuramoto [1] [2] [6] [7] [8] [9] for the fluctuation in RPS. That is, the fluctuation in RPS occurs due to environmental conditions determined by environmental factors, not as a result of the density-dependent effect.

Generally, fisheries regulation is commenced based on the concept of maximum sustainable yield (MSY); however, the concept of MSY is established based on a density-dependent effect, for which the scientific basis is questionable. I recommend that fisheries regulation should be commenced using a new concept of population fluctuation that is free from the concept of MSY.

\section{Summary}

This study showed that reproductive successes (RPS) in fish stocks could be reproduced using only environmental factors. As the environmental factors, the monthly Arctic oscillation index and Pacific decadal oscillation were used. The RPS of 12 stocks harvested around Japan were investigated. The results were as follows: the fitness between observed and reproduced $\ln (\mathrm{RPS})$, and the number of the independent variables necessary for reproducing the $\ln$ (RPS) differed by stock. However, the fluctuations of $\ln$ (RPS) could be reproduced using only the environmental factors. These results support the validity of the mechanism proposed by Sakuramoto regarding the factors that drive the fluctuation in RPS. That is, the fluctuation in RPS occurs due to conditions determined by environmental factors, and is not a density-dependent effect.

\section{Acknowledgements}

I thank anonymous reviewers for their useful comments that improved this manuscript.

\section{Conflicts of Interest}

The author declares no conflicts of interest. 


\section{References}

[1] Sakuramoto, K. (2015) A Stock-Recruitment Relationship Applicable to Pacific Bluefin Tuna and the Pacific Stock of Japanese Sardine. American Journal of Climate Change, 4, 446-460. https://doi.org/10.4236/ajcc.2015.45036

[2] Sakuramoto, K. (2015) Illusion of a Density-Dependent Effect in Biology. Agricultural Sciences, 6, 479-488. https://doi.org/10.4236/as.2015.65047

[3] Fisheries Agency and Fisheries Research and Education Agency of Japan (2020) https://www.abchan.fra.go.jp/ https://www.abchan.fra.go.jp/digest2020/index.html

[4] https://www.cpc.ncep.noaa.gov/

[5] Pacific Decadal Oscillation (PDO). http://research.jisao.washington.edu/pdo/

[6] Sakuramoto, K. (2013) A Recruitment Forecasting Model for the Pacific Stock of the Japanese sardine (sardinops Melanostictus) That Does Not Assume DensityDependent Effects. Agricultural Sciences, 4, 1-8. https://doi.org/10.4236/as.2013.46A001

[7] Sakuramoto, K. (2013) AcommonconceptofpopulationdynamicsapplicabletobothThripsimaginis (Thysanoptera) and the Pacificstockofthe Japanesesardine (Sardinopsmelanostictus). Fisheries and Aquatic Sciences, 2014, 140-151.

[8] Sakuramoto, K. (2016) A Simulation Model of the Spawning Stock Biomass of Pacific Bluefin Tuna and Evaluation of Fisheries Regulations. American Journal of Climate Change, 5, 245-260. https://doi.org/10.4236/ajcc.2016.52021

[9] Sakuramoto, K. (2016) Density-Dependent Effect Occurs Regardless of Density. Open Access Library Journal, 3, e3112. https://doi.org/10.4236/oalib.1103112 